\title{
O QUE É SER MÃE DE UMA CRIANÇA COM FIBROSE CÍSTICAa
}

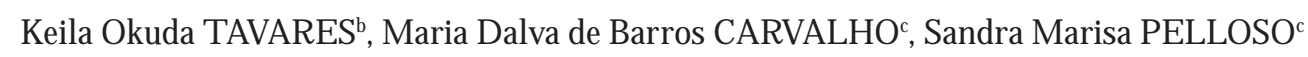

\section{RESUM 0}

Conhecer o que é ser mãe de uma criança que apresenta fibrose cística é fundamental para o cuidado desses indivíduos, pois geralmente ela divide as responsabilidades relacionadas ao tratamento com o filho que apresenta essa doença grave e sem cura. N esse sentido, este estudo teve como objetivo conhecer a vivência de ser mãe de uma criança com fibrose cística. Trata-se de um estudo descritivo-exploratório, qualitativo, de caráter fenomenológico. Foram entrevistadas 14 mulheres e a coleta de dados foi realizada por meio de uma entrevista semiestruturada. A análise das falas transcritas na íntegra seguiu direcionamentos propostos pela fenomenologia. Essa é uma experiência que a tristeza, angústia, dúvidas, sofrimento e medo estão presentes, levando essas mulheres a refletirem sobre suas vidas e a de seus filhos, promovendo mudanças em seu mundo vida e uma reorganização de toda a família.

D escritores: F ibrose cística. Relações mãe-filho. Família.

\section{RESUMEN}

Conocer lo que es ser madre de un niño con fibrosis quística es esencial para el cuidado de estas personas, porque generalmente ella divide las responsabilidades relacionadas con el tratamiento, con el niño que tiene esta enfermedad gravey sin cura. E ste estudio tuvo como objetivo conocer la vivencia de ser madre de un niño con fibrosis quística. Se trata de un estudio descriptivoexploratorio, cualitativo, fenomenológico. F ueron entrevistadas 14 mujeres y la recolección de datos se realizó por medio de una entrevista semi-estructurada. El análisis de las elocuciones transcriptas en la íntegra siguió direcciones propuestas por la fenomenología. E sta es una experiencia donde la tristeza, angustia, dudas, sufrimiento y el temor están presentes, haciendo que esas mujeres reflexionen a respecto de sus vidas y la de sus hijos, promoviendo cambios en su mundo vida y una reorganización de toda familia.

D escriptores: $\mathrm{F}$ ibrosis quística. R elaciones madre hijo. Familia.

Título: Q uésignifica ser madre de un niño con fibrosis quística.

\section{ABST RACT}

Knowing what being a mother of a child with cystic fibrosis is like is essential to the care of these individuals, because she usually divides the responsibilities related to treatment with the child who has this grave and incurable illness. This paper aimed to know the experience of being a mother of a child with cystic fibrosis. This is a descriptive exploratory study of qualitative phenomenological nature Were interviewed 14 women and the data collection was carried out through a semistructured interview. The analysis of the transcribed speeches follow ed directions proposed by phenomenology. This is an experience where sorrow, anguish, doubt, suffering and fear are present, making these women reflect on their lives and their children's, promoting changes in their world and a reorganization of the entirefamily.

D escriptors: Cystic fibrosis. M other-child relations. Family.

Title: W hat being a mother of a child with cystic fibrosis is like

\footnotetext{
a Extraído da dissertação de M estrado apresentada em 2009 ao Programa de Pós-Graduação em Ciências da Saúde da U niversidade Estadual de M aringá (UEM).

b M estre em Ciências da Saúde, D ocente do Cur so de F isioterapia da U niversidade E stadual do Oeste do Paraná (U N I OE ST E), Cascavel, Paraná, Brasil.

‘ D outora em Enfermagem, D ocente dos Programas de Pós-Graduação em Enfermagem e Ciências da Saúde da UEM, M aringá, Paraná, Brasil.
} 


\section{INT RODUÇÃO}

A fibrose cística é uma doença hereditária autossômica recessiva. U ma mutação genética determina a alteração da permeabilidade dos íons cloro na membrana apical das células exócrinas, determinando a produção de secreção espessa pelas glândulas exócrinas, dando origem a comprometimentos em órgãos como o pulmão e pâncreas ${ }^{(1)}$.

0 acometimento pulmonar dá origem a um quadro pulmonar obstrutivo progressivo. Essa alteração tem início precoce, sendo assim, também precisa de uma abordagem precoce, com a finalidade de tentar evitar o declínio da função pulmonar, os episódios de exacerbações e as mortes prematuras ${ }^{(2)}$. 0 acometimento pancreático ocasiona má digestão e consequências como a desnutrição proteico-calórica e alterações no desenvolvimento pondero-estatural ${ }^{(1)}$.

0 diagnóstico pode ser feito pela associação do quadro clínico e da avaliação da concentração de cloro no suor. Outra forma de diagnosticar é por meio da triagem neonatal(3). Com os avanços nos estudos em relação ao diagnóstico e tratamento, houve aumento na sobrevida dos pacientes. $\mathrm{Na}$ época em que foi inicialmente descrita, a expectativa de vida era de aproximadamente seis meses. Hoje, a média de idade de sobrevivência pode ultrapassar os 30 anos $^{(4)}$.

Por se tratar de uma doença sem cura, os indivíduos acometidos e suas famílias convivem com uma rotina diária de medicamentos e um tratamento que envolvem vários profissionais(5). A mãe ocupa um papel fundamental dentro da estrutura familiar, sendo uma das principais responsáveis pela educação, criação e socialização dos filhos. Frequentemente é ela que está à frente do cuidado da casa, do marido, dos filhos e da saúde da família ${ }^{(6)}$.

A equipe de saúde, geralmente, direciona suas abordagens para o corpo biológico do indivíduo com doença crônica, enfatizando os aspectos técnicos do cuidar. M uitas vezes se esquece das necessidades individuais dessas pessoas e as de seus familiares ${ }^{(7)}$. Conhecer o que é ser mãe de uma criança que apresenta fibrose cística é fundamental para o cuidado desses indivíduos, já que ela na maior parte dos casos é quem se envolve mais com o tratamento e sua continuidade no ambiente domiciliar, do que qualquer outro membro da família. G eral mente, é ela que divide as responsabilidades relacionadas ao cuidado, com o fiIho que apresenta essa doença.

E ssas informações são importantes para que o enfermeiro apresente outro olhar em relação ao processo saúde-doença dos indivíduos que apresentam a fibrose cística, não apenas o olhar técnico. Possibilita uma abordagem mais eficaz e completa, tendo como referência a mãe que é participante ativa nesse caminhar com o tratamento da doença crônica do filho. N esse sentido, este estudo teve como objetivo conhecer a vivência de ser mãe de uma criança com fibrose cística.

\section{MÉTODOS}

Trata-se de um estudo descritivo-exploratório, qualitativo, de caráter fenomenológico. Foram convidadas, a participar do estudo, todas as mães de indivíduos acometidos pela fibrose císti$\mathrm{ca}$, que estavam sendo atendidos e acompanhados no A mbulatório de Fibrose Cística do Hospital U niversitário do O este do Paraná (HUOP), local izado no município de Cascavel, Paraná(8).

As famílias foram contatadas via tel efone. $\mathrm{Na}$ ocasião, as mães foram as primeiras a serem abordadas e esclarecidas sobre o estudo, sendo questionadas sobre o seu interesse em participar dele. Para as mães que concordaram participar, foram agendadas visitas em suas residências. Foram excluídas da pesquisa as mulheres que não concordaram em participar.

A coleta de dados foi realizada nos meses de março e abril de 2009, por meio de uma entrevista semiestruturada, baseada na pergunta orientadora: "Para você, o que é ser mãe de uma pessoa que apresenta fibrose cística?". As entrevistas foram gravadas e transcritas na íntegra para posterior análise. Para melhor caracterizar essas muIheres, foi aplicado também um questionário. A pós cada visita, foram anotadas em um "diário de campo" todas as informações e impressões obtidas por meio das conversas informais com as mães e seus filhos que apresentavam a fibrose cística.

As transcrições foram identificadas pela letra "M " seguida por números, e sua análise se baseou em direcionamentos propostos pela fenomenologia: leitura de cada texto transcrito na íntegra (mergulho nas falas); leitura de cada texto, 
atendo-se à questão orientadora, para identificar "afirmações" com significados relevantes; descrição do que estava implícito nessas "afirmações" levando em consideração a questão orientadora; agrupamento das descrições com temas semelhantes determinando assim as "unidades de significado"; e por fim, a interpretação e a discussão dos dados contidos nas "unidades de significado" utilizando as informações obtidas com os "diários de campo" e o referencial teórico sobre a fibrose cística e seu tratamento(9).

Este estudo foi aprovado pelo Comitê de Ética em Pesquisa com Seres Humanos (COPEP) da U niversidade Estadual de M aringá (UEM) (Parecer $n$ - 661/2008). Todas as mães que concordaram em participar leram e assinaram um Termo de Consentimento Livre e E sclarecido (T CLE).

\section{RESULTADOS E DISCUSSÃO}

$\mathrm{Na}$ lista de pacientes do HU OP constavam os nomes de 19 indivíduos; foram encontrados quatro binômios irmão-irmão que apresentavam fibrose cística. A penas uma mãe, que apresentava dois filhos com a doença, não concordou em participar. Foram visitadas 14 famílias, seis da cidade de Cascavel e o restante de cidades próximas.

As mães apresentavam idades entre 25 e 50 anos, em média 37 anos. Em relação à forma de diagnóstico de seus filhos, em 11 das 17 crianças $(64,71 \%)$ ele foi precoce, pela triagem neonatal e em seis casos $(35,29 \%)$ tardio. Quanto à idade dos filhos que apresentavam a fibrose cística, dez $(58,82 \%)$ eram crianças, com idade entre seis meses e nove anos; cinco $(29,41 \%)$ eram adolescentes, entre 12 e 18 anos; e dois (11,76\%) eram adultos, um com 22 e o outro com 28 anos. E m relação às crianças que tiveram o diagnóstico tardio, elas apresentavam em média dez anos quando ele foi estabelecido.

E $m$ relação ao estado civil das mães, 13 $(92,86 \%)$ eram casadas e uma $(7,14 \%)$ era viúva. Quanto à escolaridade, cinco $(35,71 \%)$ apresentavam o Ensino F undamental, cinco (35,71\%) o E nsino $M$ édio e quatro $(28,57 \%)$ o Ensino Superior. E $m$ relação à profissão/ ocupação, oito $(57,14 \%)$ eram donas de casa e seis (42,86\%) exerciam al guma atividade remunerada.

A leitura e a anál ise das fal as per mitiu a identificação de três unidades de significado descritas a seguir.

\section{O diagnóstico da fibrose cística: se deparando com o desconhecido}

No caso das mães entrevistadas, foi difícil e assustador receber a notícia que 0 filho apresentava uma doença grave e sem cura, que até então nunca tinham ouvido falar. Elas se depararam com uma situação inesperada e não-planejada ao saberem que teriam que conviver com a fibrose cística e seu tratamento para o resto de suas vidas. Algumas relataram tristeza, desespero, nervosismo, revolta. Outras não aceitaram o diagnóstico, principalmente por causa do prognóstico. M uitas se emocionaram ao relatar essa vivência, lembrando que se sentiram desamparadas e perdidas.

As mães que tiveram o diagnóstico tardio, também relataram o mesmo, porém, receber essa notícia proporcionou certo conforto, pois durante muito tempo sofreram ao ver os filhos apresentando problemas de saúde e recebendo tratamentos que não produziam resultados satisfatórios. Sentiram-se al iviadas em saber que a partir de então, seus filhos seriam tratados de forma correta.

[ ...] P ra mim foi um choque muito grande $\mathrm{N}$ o começo eu chorei muito. $\mathrm{N}$ o dia que me deram o diagnóstico, eu e meu esposo, nós choramos muito (M 9).

[ ...] foi um susto, eu fiquei muito nervosa assim, irritada [...] (M 4).

[ ...] eu não aceitava que a minha filha fosse chegar no máximo na adol escência [ ...] (M 7).

[...] era sofrimento com ela, ver ela sofrendo, sempre internada, uma coisa ou outra. E u lutei muito pra conseguir descobrir o problema dela (M 14).

Durante a gestação, a mulher tem várias expectativas em relação ao bebê que vai nascer. Quando ela fica sabendo após o nascimento, que o filho idealizado apresenta o diagnóstico de uma doença crônica, se inicia um processo de luto pela perda do filho imaginário. Existem as fase do choque, da negação, do reconhecimento da perda e da gradativa aceitação e adaptação(10).

0 luto pela perda do filho idealizado, mesmo sendo doloroso, é necessário para a aceitação do filho real. 0 respeito em relação aos seus sentimentos e a compreensão desse momento nãoplanejado em sua vida auxilia o enfrentamento e ameniza o impacto do nascimento de um filho com 
doença crônica(11). Este é um momento de fragilidade e a mulher necessita compartilhar sua dor e seu pesar para diminuir o sofrimento e aceitar 0 problema. No entanto, cada uma pelas suas atitudes e falas vai demonstrar o momento mais oportuno para que seja possível uma aproximação(12).

0 choque ao receber o diagnóstico é grande, porque a família se depara com uma doença grave e incurável. A princípio, a família não sabe administrar a situação, pois ainda não conhece a doença, suas consequências e seu tratamento. Os pais não sabem se vão conseguir ajudar seu filho e experimentam uma alteração dos seus projetos existenciais e uma falta de controle sobre o futuro da criança ${ }^{(13)}$.

Receber essa notícia não é fácil, especialmente para a mãe, e a elaboração da perda do filho idealizado é permeada de conflitos. Essa é uma experiência única e intransferível, marcada pelo choro, desespero e ansiedade ${ }^{(14)}$. As mães podem se sentir incompletas, incapazes e apresentarem ideias depressivas ${ }^{(15)}$.

Os relatos e comportamentos dessas mulheres frente às alterações e adaptações impostas pela doença devem ser valorizados. 0 diálogo é o primeiro passo em direção ao entendimento da sua experiência ${ }^{(16)}$. M ães nessa situação se mostram receptivas diante da possibilidade de serem ouvidas. Sendo assim, faz sentido ir ao encontro delas, procurando escutá-las e refletir com elas sobre o sentido que elas atribuem a sua vivência. 0 luto mal vivido e elaborado pode afetar o diaa-dia dessas mulheres, interferir nas suas atividades, prejudicar a interação com o filho, provocar sofrimento intenso e possibilitar o aparecimento de problemas psíquicos no futuro(15).

\section{Conhecendo a fibrose cística: a busca do equilíbrio e adaptação}

Foi possível observar que as mulheres entrevistadas passaram a refletir sobre seu papel na vida do filho, a partir do diagnóstico. Elas construíram uma nova figura de mãe, a mãe de uma criança com fibrose cística. A partir daí, elas atribuíram um novo significado às suas vidas. Perceberam a necessidade de aceitar a situação e se adaptar, porque os filhos dependiam delas. Elas procuraram adquirir equilíbrio, e apesar de apresentarem as sensações de medo e impotência fren- te à doença, se agarraram à esperança de vencêla, buscando motivação para suas tomadas de decisão(17).

P orque, porque não tem outro jeito. A gente tem que conviver com isso daí. Tem que conviver agora com isso daí e fazer o tratamento cer to (M 5).

N o começo tudo foi difícil, quenem eu estou tefalando. $M$ as depois eu fui me adaptando, porque eu sabia que ela dependia de mim (M 9).

A pós "aceitar" o diagnóstico da doença crônica, a mãe tenta retomar o controle da situação, buscando informações sobre 0 assunto, procurando adquirir conhecimento com o objetivo de esclarecer suas dúvidas ${ }^{(13)}$. A partir do momento que a família aprende a lidar com a fibrose cística e a visualizar resultados positivos com a sua intervenção, passa a se sentir mais segura(18).

Q uando cheguei lá, que conversei, que conheci as pessoas que já tinham bastante conhecimento sobre isso, aí foi que eu comecei a ter mais calma [ ...] (M 6).

Agora com o passar dos anos, a gente já foi acostumando, até que eu acho assim quase que nor mal. $\mathrm{N}$ ormal não é porque ela tem esse problema, mas não acho assim tanta dificuldade pra cuidar dela (M 13).

A o conviver com a criança, a fibrose cística e sua rotina de tratamento, elas começaram a visualizar que enfrentar a situação não seria tão difícil como elas imaginaram, pois passaram a experimentar um "controle" sobre a doença. No início, o choque causado pelo diagnóstico não per mitiu que elas tivessem uma visão ampla do problema. Com o tempo desenvolveram estratégias de enfrentamento e novas habilidades para poderem cuidar dos filhos.

E u tive que aprender o que era a fibrose cística, como lidar, como fazer as fisioterapias, levar ela, procurar uma pneumo [ ...] , me acostumar com isso (M 9).

E eu mesmo já manipulo a medicação toda, só não pe go a veia, o resto eu faço sabe (M 7).

Para essas mulheres, não ter conhecimento sobre a doença e seu tratamento significa não saber como proceder. A disponibilidade para responder aos seus questionamentos contribui para uma adaptação saudável|(14). Conhecer os integran- 
tes do núcleo familiar, as relações entre el es e como cada um participa do cuidado do indivíduo com a doença crônica, é um importante fator que facilita o processo de adaptação, pois geralmente existe a sobrecarga da figura mater na ${ }^{(19)}$.

A família é uma das principais referências de amor, confiança e existência do ser doente. Como parte responsável pela saúde de seus membros, deve ser estimulada a participar ativamente de todo o processo de cuidar/ curar. Torna-se necessário verificar como se dá esse cuidar em família, na busca de uma estratégia que seja mais adequada a cada situação. A pesar das famílias enfrentarem problemas semelhantes quando um de seus integrantes apresenta uma doença, cada uma delas apresenta suas necessidades, que por sua vez são resultados de suas particularidades e realidades ${ }^{(20)}$.

Tentar proporcionar o contato com outras pessoas que passam pelo mesmo problema também pode auxiliar na adaptação, diminuir a ansiedade e ajudar no enfrentamento. É importante ampliar a rede de apoio dessas famílias, pois ao conhecerem indivíduos que vivenciam o mesmo problema, acabam trocando informações e experiências, passando a perceber que não são as únicas pessoas a ter em que enfrentar a mesma realidade ${ }^{(18)}$.

\section{Conviver com o filho que apresenta a fibrose cística: redimensionando o cuidado de mãe}

As mulheres entrevistadas relataram que além das preocupações que todas as mães apresentam em relação aos filhos, elas têm outras preocupações adicionais, como as frequentes visitas aos profissionais da saúde, o cumprimento do tratamento medicamentoso e fisioterapêutico, a prevenção de complicações da doença. Elas relatam que apresentam rotinas diferentes das outras mães, no sentido de apresentar mais responsabilidades, mais tarefas a cumprir, mais deveres para com o filho.

[ ...] éser mãeacho queduplamente. A ssim, muito mais responsável, tem que ser muito mais que uma mãenormal. T em que estar sempre preocupada vinte e quatro horas. Semprequalquer coisinha, sempreantenada, sempre estar assim ligada. Você não pode descuidar um minuto de nada, em relação a ela (M 2).

Por causa da convivência com a fibrose císti$\mathrm{ca}$, as mães apresentam uma visão mais apurada dos aspectos clínicos e emocionais, das reações e necessidades de seus filhos ${ }^{(18)}$. Elas estão vigilan- tes $24 \mathrm{~h}$ por dia, prestam atenção em tudo, e a qualquer sinal e/ ou sintoma é percebido prontamente e monitorado por elas com extrema preocupação. É como se somente elas conseguissem compreender os filhos e cuidar deles da maneira certa. As mães apresentam toda essa preocupação por terem medo de perder o filho.

Quando eu vejo que ela não está bem, que ela está sonolenta, que ela não está legal, eu já corro na médica, eu já incomodo mesmo, ligo [ ...] (M 9).

Que nem ontem, ela teve um pouquinho de tosse, uma crisezinha a noite Aí quando ela tem isso eu não durmo sabe $\mathrm{N} o$ outro dia eu tenho que trabalhar [ ...] (M 10).

[ ...] a gente precisa sempre estar em observação, cuidando pra não causar mais, além daquilo, dos prejuízos que ela já tem, não ter outros por cima. E ntão a gente sempre fica cuidando, então écomo se fosse uma jóia que a gente vai lapidando aos pouquinhos, cuidando, conservando, anal isando daqui, tentando consertar dali, para ela ter uma vida saudável (M 12).

Pelo fato da fibrose cística ser uma doença que acomete vários órgãos, ela requer um cuidado complexo e contínuo e uma atenção em tempo integral, visando uma evolução clínica estável. A mãe geralmente gasta muito tempo em atividades relacionadas ao tratamento dos filhos em comparação a outras atividades relacionadas ao ambiente doméstico(18).

Ela supervaloriza o seu cuidado e reconhece que ele é diferenciado, justificando isso por causa da gravidade da doença. A morte é mais provável para essas crianças, e o medo parte faz parte do seu cotidiano. Com o passar do tempo, ela pode apresentar dificuldades em deixar o filho livre para tomar conta de si mesmo e ser mais independente. $\mathrm{Na}$ maior parte dos casos entende que o papel de cuidadora é exclusivamente seu, não dividindo a responsabilidade com os demais membros da família, sendo superprotetora.

E m outros casos, o próprio filho não permite que outras pessoas se envolvam no cuidado. É importante a união da família, pois esse indivíduo precisa se sentir amparado e saber que pode contar com seus pais e irmãos. Todos devem ser parceiros nesse caminhar com a doença crônica. Em alguns lares, a superproteção da mãe pode acarretar problemas de relacionamento com o cônju- 
ge, com os outros filhos e também entre os filhos. Esses conflitos precisam ser evitados para que 0 indivíduo que apresenta a fibrose cística não venha a se sentir culpado pelas alterações nas relações familiares.

[ ...] eu fazia tudo por ela, não deixava espaço pro pai dela sabe [...] Hoje eu vejo assim, que quando eu abri espaço pra ele, ele veio mais sabe, e ajuda mais, isso pra ela foi muito bom. A união, a unidadedo pai eda mãe, de toda a família. Que isso pra eles é fundamental, eles saber em que tem um pai e uma mãe que eles podem contar (M 07).

As pessoas que apresentam a fibrose cística precisam ser estimuladas a participar ativamente do tratamento à medida que crescem com a doença, pois também são responsáveis pela sua saúde. A lgumas das mães entrevistadas já apresentam a preocupação de que os filhos ao se separarem dela, não continuem a realizar o tratamento da forma correta, outras relataram que os filhos já apresentam resistência à rotina e horários impostos pela medicação. Se hoje uma expectativa maior de vida pode ser possível, ela é resultado de muitos estudos visando um tratamento eficiente, que para manifestar os resultados esperados, deve ser conduzido de forma correta para o resto da vida.

[ ...] quando éum bebezinho, o que vocêfaz, fez. M as agora eles são... T ipo assim, às vezes ela é tei mosinha pra fazer inalação, às vezes passa da hora de tomar 0 remédio. D aí tem que estar falando [ ...] (M 13).

[ ...] agora está reinando um pouco, porque está entrando na adolescência. M as assi $m$, tem que tomar re médio, toma. F az um drama pra tudo [ ...] (M 02).

No caso das famílias entrevistadas foi possível observar que os indivíduos que apresentam a fibrose cística encaram de forma saudável a sua condição. As crianças referem que são normais e que precisam de cuidados especiais, que por sua vez não limitam suas atividades diárias. Já os adolescentes percebem que a rotina é estressante e que algumas atividades que uma pessoa da mesma idade realiza, el es nem sempre conseguem realizar da mesma forma. $M$ as em nenhum momento eles relatam que apresentam o risco de morrer precocemente caso não cumpram o tratamento correto.

Provavelmente essa forma de visualizar a doença seja o reflexo da atitude dos pais frente à si- tuação. $\mathrm{N}$ as visitas observou-se que os pais, apesar de considerarem a rotina de tratamentos cansativa, conseguiam administrar bem essa questão, demonstrando que desenvolveram estratégias de enfrentamento. I sso contribuiu para que os filhos vivenciassem a fibrose cística de uma maneira positiva, favorecendo o desenvolvimento esperado para cada faixa etária(18).

\section{CONSIDERAÇÕES FINAIS}

Receber o diagnóstico da fibrose cística é um acontecimento doloroso na vida dessas mulheres, marcado pela tristeza, angústia e dúvidas. Elas se sentem fragilizadas frente à atitude de profissionais que se limitam apenas a comunicar que seus filhos apresentam uma doença grave e incurável. M uitos não observam a dimensão emocional do problema e não proporcionam meios para que elas possam manifestar seus sentimentos. E star disponível para responder seus questionamentos e orientá-las, pode amenizar seu sofrimento e contribuir para a aceitação do problema.

A partir do diagnóstico, todas passaram a refletir sobre o seu papel na vida do filho e a construir uma nova figura de mãe. Foi possível perceber que atribuíram um novo sentido às suas vidas, pois sabiam que era necessário se adaptarem, porque os filhos dependiam delas. Essa experiência afetou o mundo vida dessas mulheres e modificou a dinâmica familiar. T odos acabaram se envolvendo, em maior ou menor intensidade, com esse processo de conhecer e aprender a conviver com a fibrose cística. Com o tempo as famílias desenvolveram suas estratégias de enfrentamento e novas habilidades para poder cuidar dos filhos que apresentam essa doença crônica.

$\mathrm{N}$ a maior parte dos casos, a mãe é superprotetora, pois o medo da morte faz parte do seu cotidiano. Elas apresentam resistência em deixarem seus filhos mais independentes pelo medo de perdê los, porém el es precisam ser estimulados a participar ativamente do tratamento à medida que crescem e a encarar 0 autocuidado como al go essencial em suas vidas.

A aproximação maior dessas mães permiteao enfermeiro um cuidado mais completo, não voltado somente para a técnica, mas para a prática social. É necessário ter sensibilidade e ir ao encontro dessas mulher es para perceber e compreender que essas famílias vivenciam várias dificuldades a par- 
tir do momento em que ficam sabendo do diagnóstico da doença. Compreender como acontece o processo de adaptação em cada caso permite que diferentes abordagens sejam desenvolvidas, com 0 intuito de estar auxiliando essas pessoas nesse seu caminhar com a doença crônica, pois outros episódios de estresse e crise relacionados à fibrose cística certamente acontecer ão.

Sugerem-se, para estudos futuros, pesquisas de cunho qual itativo envolvendo o indivíduo com fibrose cística, a fim de conhecer sua vivência com a doença crônica e complementar os dados obtidos no presente estudo, com o intuito de mel horar ainda mais a assistência do enfermeiro e outros profissionais da saúde.

\section{REFERÊNCIAS}

1 Ribeiro JD, Ribeiro M AG 0, Ribeiro AF. Controvérsias na fibrose cística: do pediatra ao especialista. J Pediatr. 2002;78(2):171-86.

2 Accurso FJ. U pdate in cystic fibrosis 2006. A m J Respir Crit Care M ed. 2006;173(9):944-7.

3 M inistério da Saúde (BR ), Secretaria de A ssistência à Saúde, Coordenação-G eral de A tenção E specializada. $M$ anual de normas técnicas e rotinas operacionais do programa nacional de triagem neonatal. Brasília (DF ); 2002.

$4 \mathrm{D}$ avis PB. Cystic fibrosis since 1938. A mJ Respir Crit Care M ed. 2006;173(9):475-82.

5 Ribeiro RLR, Rocha SM M . Enfermagem e família de crianças com síndrome nefrótica: novos el ementos e horizontes para o cuidado. Texto Contexto Enferm. 2007;16(1):112-9.

$6 \mathrm{M}$ artin $\mathrm{VB}$, A ngelo M . A organização familiar para 0 cuidado dos filhos: percepção das mães em uma comunidade de baixa renda. Rev L atino-A m E nfermagem. 1999;7(4):89-95.

7 Silva JB, Kirschbaum DIR, Oliveira I. Significado atribuído pelo enfermeiro ao cuidado prestado à criança doente crônica hospitalizada acompanhada de familiar. Rev G aúcha E nferm. 2007;28(2):250-9.

\author{
Endereço da autora / Dirección del autor / \\ Author's address: \\ Keila Okuda T avares \\ Rua Paraná, 2447 \\ 85812-011, Cascavel, PR \\ E - mail: keilaokudatavares@gmail.com
}

8 T avares KO. F ibrose cística: os múltiplos olhares para o ser fibrocístico [ dissertação] . M aringá: U niversidade Estadual de M aringá; 2009.

9 Giorgi AP. Phenomenology and psychological research. Pittsburgh: D uquesne U niversity P ress; 2003.

10 Voidivic M A M A, Storer M RS. 0 desenvolvimento cognitivo das crianças com Síndrome de D own à luz das relações familiares. Psicol T eor P rát. 2002;4(2): 31-40.

11 Boff J, Caregnato RCA. H istória oral de mulheres com filhos portadores de Síndrome de D own. T exto Contexto Enferm. 2008;17(3):578-86.

12 L oureiro M F F. 0 sentido do comportamento materno diante da morte do filho. Fortaleza: U F C; 1998.

13 D amião E BC, A ngelo M . A experiência da família ao conviver com a doença crônica da criança. Rev E sc Enferm USP. 2001;35(1):66-71.

14 Barbosa M AM, Chaud M N, G omes M M F. Experiences of mothers of disabled children: a phenomenological study. Acta Paul E nferm. 2008;21(1):46-52.

15 Battikha E C, Faria M CC, Kopelmann BI. As representações maternas acerca do bebê que nasce com doenças orgânicas graves. P sicol T eor Pesqui. 2007; 23(1):17-24.

16 A raújo M TA, Silva M J P, Puggina A CG . A comunicação não-verbal como fator iatrogênico. Rev Esc E nferm USP. 2007;41(3):419-35.

17 M oreira PL, Ângelo M . Tornar-se mãe de criança com câncer: construindo a parentalidade. Rev Latino-Am E nfermagem. 2008;16(3):355-61.

18 F urtado M CC, Lima RAG. 0 cotidiano da família com filhos portadores de fibrose cística: subsídios para a enfermagem pediátrica. Rev L atino-A m E nfermagem. 2003;11(1):66-73.

19 G uimarães T M R, M iranda W L, T avares M M F. 0 cotidiano das famílias de crianças eadol escentes portadores de anemia falciforme. Rev Bras Hematol H emoter. 2009;31(1):9-14.

20 Resta D G, Budó M LD. A cultura e as formas de cuidar em família na visão de pacientes e cuidadores domiciliares. A cta Sci, Health Sci. 2004;26(1):53-60.

Recebido em: 29/04/2010

A provado em: 11/ 12/ 2010 